\title{
Taxonomic reassessment of Clevosaurus latidens Fraser, 1993 (Lepidosauria, Rhynchocephalia) and rhynchocephalian phylogeny based on parsimony and Bayesian inference
}

\author{
Jorge A. Herrera-Flores, Thomas L. Stubbs, Armin Elsler, and Michael J. Benton
}

School of Earth Sciences, University of Bristol, Queens Road, Bristol BS8 1RJ, UK 〈jorge.herreraflores@bristol.ac.uk〉〈tom.stubbs@bristol.ac.uk〉 $\langle$ armin.elsler@bristol.ac.uk〉〈mike.benton@bristol.ac.uk〉

\begin{abstract}
The Late Triassic rhynchocephalian Clevosaurus latidens Fraser, 1993 is known from the fissure deposits of Cromhall Quarry, England. Many studies have questioned its referral to the genus Clevosaurus Swinton, 1939 and some phylogenetic analyses suggest a close relationship with herbivorous rhynchocephalians. We re-examine the type specimens and referred material of $C$. latidens to elucidate its taxonomic identity. Additionally, we provide new phylogenetic analyses of the Rhynchocephalia using both parsimony and Bayesian approaches. Our taxonomic review and both phylogenetic analyses reveal that $C$. latidens is not referable to Clevosaurus, but represents a new genus. We reassess $C$. latidens and provide an amended diagnosis for Fraserosphenodon new genus. Both parsimony and Bayesian analyses recover similar topologies and we propose formal names for two higher clades within Rhynchocephalia: Eusphenodontia new infraorder and Neosphenodontia new clade.
\end{abstract}

UUID: http://zoobank.org/65f29bd1-47e3-4a73-af8c-9181c19319e4

\section{Introduction}

The Rhynchocephalia is an ancient group of reptiles that originated in the early Mesozoic. Currently this group has low diversity, being represented by a single species, the famous 'living fossil' Sphenodon punctatus (Gray, 1842) from New Zealand (Jones et al., 2013; Cree, 2014; Herrera-Flores et al., 2017). In contrast to their current low diversity, Mesozoic rhynchocephalians were diverse, showing varied morphologies and a wide geographical distribution (Jones, 2006a, 2009; Rauhut et al., 2012; Martínez et al., 2013; Herrera-Flores et al., 2017). Among the earliest rhynchocephalians, species of the genus Clevosaurus Swinton, 1939 were the most diverse and widely distributed in the early Mesozoic. Clevosaurus hudsoni Swinton, 1939 was the first described species of the genus; it was named after F. G. Hudson, who discovered the fossil remains at Cromhall Quarry, England (Fraser, 1988). Since the description of $C$. hudsoni, nine species of Clevosaurus have been erected-C. bairdi Sues, Shubin, and Olsen, 1994, C. brasiliensis Bonaparte and Sues, 2006, C. convallis Säilä, 2005, C. latidens Fraser, 1993, C. mcgilli Wu, 1994, C. minor Fraser, 1988, C. petilus Young, 1982, C. sectumsemper Klein et al., 2015, and C. wangi Wu, 1994-and new records have been reported from localities in Belgium, Brazil, Canada, China, Great Britain, Mexico, and South Africa (Fraser, 1988, 1993; Wu, 1994; Sues et al., 1994; Duffin, 1995; Sues and Reisz, 1995; Säilä, 2005; Bonaparte and Sues, 2006; Reynoso and Cruz, 2014; Klein et al., 2015).

The anatomy of Clevosaurus is well known and the monograph of Fraser (1988) offers a very thorough review of the general morphology of this genus. It is recognized that the genus Clevosaurus is highly diverse, but the taxonomic validity of some Clevosaurus species has been questioned (Jones, 2006a). Hsiou et al. (2015) presented a review of $C$. brasiliensis that included a phylogenetic analysis of almost all known Clevosaurus species. Their study demonstrated that some species might not be valid taxa or are perhaps not directly referable to this genus. One of these conflicting taxa is $C$. latidens, a species described by Fraser (1993) from the Late Triassic fissure deposits of Cromhall Quarry, England. The uncertain taxonomic affinity of $C$. latidens and its dubious relationship with Clevosaurus have been noted in many previous studies (Jones, 2006a, 2009; Martínez et al., 2013; Hsiou et al., 2015; Klein et al., 2015), and some phylogenetic analyses even suggested a closer relationship with opisthodontians, but no taxonomic revision of this taxon has been carried out.

For a long time, the relationships among rhynchocephalians were poorly known, and most taxa were assessed by overall morphological similarities. The first phylogenetic analysis of the group was performed by Fraser and Benton (1989), followed by many different analyses, including new descriptions or redescriptions of taxa (e.g., Wu, 1994; Reynoso, 1996, 1997, 2000, 2005; Reynoso and Clark, 1998; Apesteguía and Novas, 2003; Rauhut et al., 2012; Martínez et al., 2013; Apesteguía and Carballido, 2014; Apesteguía et al., 2012, 2014; Cau et al., 2014; Hsiou et al., 2015). So far, all phylogenetic studies of the Rhynchocephalia have only used parsimony analysis, recovering a few distinct clades. More recently, Bayesian inference methods have been employed for phylogenetic analyses based on morphological characters (e.g., Parry et al., 2016; Wright, 2017), and recent studies suggest that Bayesian 
methods outperform parsimony for morphological data (O’Reilly et al., 2016; Puttick et al., 2017), recovering more accurate, but less precise results.

To clarify the doubtful taxonomic affinity of Clevosaurus latidens, we re-examined the type specimens and other material described by Fraser (1993). We updated the character matrix of a recent phylogenetic analysis of the Rhynchocephalia (Hsiou et al., 2015), recoded morphological characters for $C$. latidens, and performed both parsimony and Bayesian analyses. Our results confirm that $C$. latidens is not related to Clevosaurus, but represents a new genus. Our phylogenetic analyses recover similar topologies using both parsimony and Bayesian approaches. We employ the new phylogeny to propose formal names for two higher clades within Rhynchocephalia.

\section{Material and methods}

We re-examined the type material and other material described by Fraser (1993) as Clevosaurus latidens. All specimens of C. latidens consist of fragments of dentary, maxilla, and premaxilla housed in the collections of the Virginia Museum of Natural History and the University of Aberdeen. For anatomical comparisons, we reviewed several specimens of Clevosaurus from the paleontological collections of the University of Bristol and the University Museum of Zoology in Cambridge.

To explore the phylogenetic relationships of rhynchocephalians and the position of Clevosaurus latidens, we used the largest and most up-to-date data matrix of Rhynchocephalia (Hsiou et al., 2015). We added three taxa-C. sectumsemper Klein et al., 2015, Derasmosaurus pietraroiae Barbera and Macuglia, 1988, and Priosphenodon minimus Apesteguía and Carballido, 2014-and recoded some characters for C. latidens and Pelecymala robustus Fraser, 1986 after examination of the type specimens. The new matrix comprises 47 operational taxonomic units scored for 74 characters. We rooted the trees with the lepidosauromorph Sophineta cracoviensis Evans and Borsuk-Bialynicka, 2009. Two squamates, the Late JurassicEarly Cretaceous Eichstaettisaurus Kuhn, 1958 and the extant Pristidactylus Gray, 1845, were also used as outgroups.

The revised taxon-character data matrix was analyzed using both equally weighted maximum parsimony and Bayesian inference. Parsimony analysis was performed in TNT v. 1.5 (Goloboff et al., 2008; Goloboff and Catalano, 2016), first using the 'New Technology' search options. The initial tree search used multiple replications with sectorial searches, four rounds of tree fusing, 10 rounds of drifting, and 200 ratcheting iterations. Following this, the generated most parsimonious trees (MPTs) were analyzed using traditional tree bisection and reconnection branch swapping. All recovered MPTs were then summarized in a 50\% majority rule consensus tree, and clade robustness was assessed with Bremer decay indices (Bremer, 1994). Bayesian inference trees were estimated using MrBayes v. 3.2 (Huelsenbeck and Ronquist, 2001; Ronquist et al., 2012). The standard Mk model (Lewis, 2001) with gamma distribution priors for site rate variation was specified. The analysis was performed with four runs of four chains, run for $10^{8}$ generations, sampling parameters every 1000 generations. The first $25 \%$ of sampled trees were discarded as burn-in. Convergence was assessed based on effective sample size (ESS) values $>200$. Results from the Bayesian analysis were summarized using a 50\% majority consensus tree, revealing clades that have posterior probability values of $\geq 50 \%$. The data matrix and analytical scripts are included in the Supplementary Data Set.

Repositories and institutional abbreviations.-AUP = University of Aberdeen Paleontology Collection; BRSUG= Bristol University, School of Earth Sciences Collection; NMS = National Museums Scotland; SAMK = South African Museum; UMZC = University Museum of Zoology, Cambridge; $\mathrm{VMNH}=$ Virginia Museum of Natural History.

\section{Systematic paleontology}

Superorder Lepidosauria Haeckel, 1866

Order Rhynchocephalia Günther, 1867

Suborder Sphenodontia Williston, 1925

Infraorder Eusphenodontia new infraorder

Remarks.-See Discussion.

Clade Neosphenodontia new clade

Remarks.-See Discussion.

Clade Opisthodontia Apesteguía and Novas, 2003

Genus Fraserosphenodon new genus

urn:Isid:zoobank.org:act:6C14E307-718C-47C8-AC8FC658A048289B

Type species.—Clevosaurus latidens Fraser, 1993.

Diagnosis for the genus and only known species.-Moderatesized rhynchocephalian. Maxillary teeth with relatively short crowns with transversely broadened posterolabial flanges without grooved facets on the labial surface. Robust dentary with a wide mandibular symphysis. Dentary with three generations of teeth. Front of dentary with two rounded successional teeth followed by a series of six or seven very small rounded hatchling teeth. Additional teeth in dentary transversely broadened distinctly triangular in labial view and rounded and bulbous in occlusal view.

Etymology.-The genus epithet is in honor of the British paleontologist Nicholas 'Nick' Fraser, for his outstanding contributions to the knowledge of the British Triassic fauna, especially for his exceptional work on early rhynchocephalians.

Occurrence.-Cromhall Quarry, Avon, England, site 5A of Late Triassic fissure deposit.

Remarks.-All Fraserosphenodon specimens are quite fragmentary, but their tooth morphology, based on wide and robust teeth for grinding, clearly differs from the tooth shape for cutting and slicing characteristic of the genus Clevosaurus, and, indeed, is more similar to that of opisthodontians.

Fraserosphenodon latidens (Fraser, 1993) new combination Figures 1-2 
1986 aff. Pelecymala; Fraser, p. 176, pl. 20, figs. 8, 9.

1988 Clevosaurus sp.; Fraser, p. 163, fig. 43.

1993 Clevosaurus latidens Fraser, p. 137, fig. 2.

Holotype.-VMNH 524, maxillary fragment (Fig. 1.1-1.3).

Additional specimens.—VMNH 525-528, AUP 11191-11192.

Remarks.-The systematic paleontology section of Fraser's original work referred to the holotype of Fraserosphenodon latidens (VMNH 524) as a dentary fragment (Fraser, 1993), but the description of this element treated it as a maxillary fragment. Our review of VMNH 524 confirms that it is a fragment of the posterior part of the left maxilla (Fig. 1.1-1.3). This element includes five well-preserved, complete teeth. The maxillary teeth have relatively short crowns with transversely broadened posterolabial flanges without grooved facets on the labial surface and heavily worn occlusal surfaces.

We agree with Fraser (1993) that paratype specimen VMNH 525 is a dentary fragment that possibly belongs to the right dentary (Fig. 1.4-1.6). This element has three teeth that are also transversely broadened. In labial view, all teeth appear distinctly triangular. Only the second and third teeth are heavily worn, and the wear is especially pronounced on the third tooth. In occlusal view, the teeth of VMNH 525 appear round with a bulbous swelling developed medially on each tooth, as was described by Fraser (1993) for specimen VMNH 543. The overall shape of both VMNH 525 and 543 is also quite similar. Note that Fraser (1993) did not mention specimen VMNH 543 in the systematic paleontology section of his paper, and there is also no specimen in the VMNH collection assigned to Fraserosphenodon (C. latidens) with that catalog number. It might be that specimen VMNH 543 illustrated and described by Fraser (1993, fig. 2C-E) is indeed specimen VMNH 525.

Paratypes VMNH 526-528 are maxillary fragments (Fig. 1.7-1.15). Specimens VMNH 526 and 528 (Fig. 1.7-1.9, 1.13-1.15) belong to the distal part of the left maxilla, whereas VMNH 527 (Fig. 1.10-1.12) belongs to the mesialmost part of the right maxilla. VMNH 526 and 528 include a series of four complete teeth, which are heavily worn on the occlusal surface, and have a morphology comparable to that of the holotype. The crowns of VMNH 528 are a little higher than in the other specimens (Fig. 1.13-1.15). VMNH 527 includes six complete teeth and a very small fragment of a broken tooth in the distal part of the element (Fig.1.10-1.12). The mesialmost tooth of this specimen is very small and rounded; the following tooth is also very small and of a semioval shape. The third to sixth teeth are all transversely broadened, with a right-angled triangular shape in labial view and a heavily worn occlusal surface. Paratype VMNH 529, a maxillary fragment according to Fraser (1993), could not be located within the VMNH collection.

The heavily worn occlusal tooth surfaces in all type specimens suggest that they might belong to adult individuals (Fig. 1). A recent study of ontogenetic variation of the dentary in rhynchocephalians (Romo de Vivar-Martínez and Bento-Soares, 2015) demonstrates that the occlusal surface of teeth shows high wear in mature specimens.
Additionally, another six specimens from the AUP collection can be referred to Fraserosphenodon. However, apart from AUP 11191 and 11192 (premaxilla and dentary, respectively), the other four specimens attributable to Fraserosphenodon are all fragmentary maxillary elements. All of these maxillary elements were stored in containers with other rhynchocephalian specimens without being labeled individually, making it impossible to associate the specimens with unique catalog numbers. These specimens all clearly exhibit the characteristic transversely broadened tooth morphology without grooved facets on the labial tooth surfaces, with heavy wear on the occlusal surface. The first specimen is a fragment of a right maxilla. It has four heavily worn teeth that include a small rounded tooth between the second and third tooth, which might represent a dental pathology. The second specimen is a fragment of a right maxilla that includes two isolated but complete teeth. The third specimen is a fragment of a right maxilla and includes four teeth. The mesialmost tooth of this specimen is heavily eroded and the tooth enamel of the third tooth is slightly damaged. The fourth specimen is a fragment of the distal end of a left maxilla; it includes two teeth with very short crowns due to the heavy wear of the occlusal surface. Among all rhynchocephalian specimens in the AUP collection, we did not identify any dentary specimens attributable to Fraserosphenodon with preserved coronoid processes (contra Fraser, 1993).

Specimen AUP 11191, a right premaxilla (Fig. 2.1, 2.2), was originally identified as Clevosaurus sp. by Fraser (1988) and was subsequently reassigned to $C$. latidens by Fraser (1993). The nasal process is broken in AUP 11191, but the ventral and dorsal maxillary processes are well preserved. The distal end of the ventral maxillary process has a clearly flattened oval shape; the dorsal maxillary process is relatively long and is angled at $\sim 60^{\circ}$ relative to the ventral maxillary process. On the convex dorsal surface of the premaxilla, between the dorsal maxillary process and the nasal process, it is possible to observe the premaxillary fossa, which is semicircular in shape. AUP 11191 exhibits three complete teeth, of which the distalmost tooth is very small, considerably shorter in relation to the other two teeth. In contrast, the two mesialmost teeth are of regular size and partially fused, and both have a rounded semicircular shape with minor signs of wear. The semifused condition of the two mesialmost teeth of AUP 11191 suggests that this specimen is a juvenile: as seen in other derived rhynchocephalians (e.g., Clevosaurus and Sphenodon spp.) these teeth fuse over time in mature individuals to form the characteristic chisel-like structure seen in late-diverging rhynchocephalians (Robinson, 1973).

Specimen AUP 11192, an anterior fragment of a right dentary (Fig. 2.3-2.5), was tentatively assigned to Pelecymala Fraser, 1986 by Fraser (1986), but as in the case of AUP 11191, it was later referred to $C$. latidens by Fraser (1993). In the description of AUP 11192, Fraser (1986) noticed that the length of this specimen appeared quite similar to that of $C$. hudsoni, but was noticeably deeper in height. AUP 11192 has a robust and deep structure, similar to that of opisthodontians (e.g., Priosphenodon Apesteguía and Novas, 2003, Toxolophosaurus Olson, 1960). The mandibular symphysis in AUP 11192 is quite wide; the Meckelian canal runs along the midline of the jaw. 
1

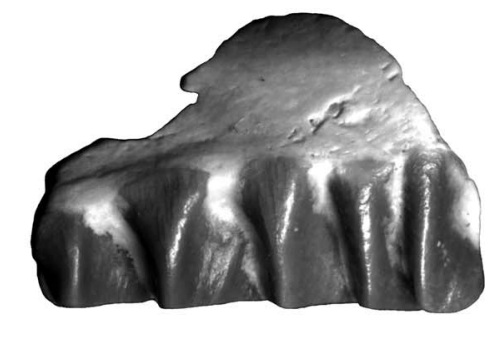

4

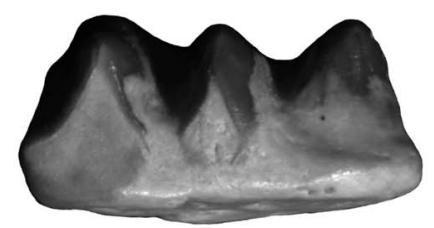

7

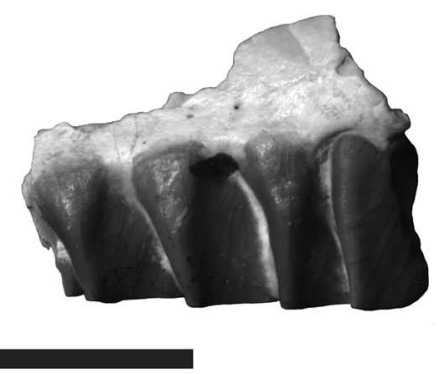

10

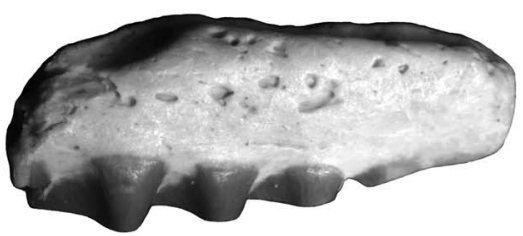

13

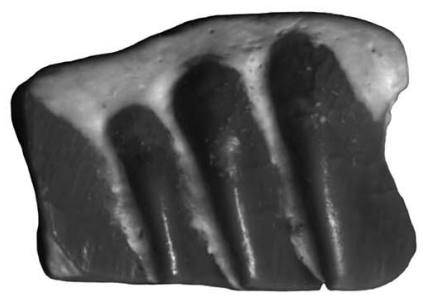

2

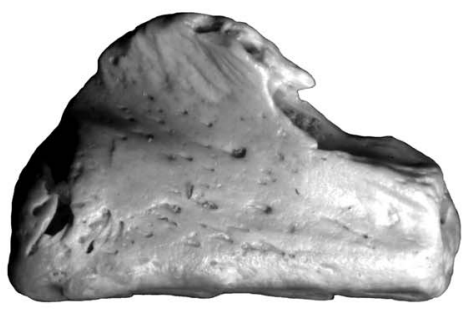

5

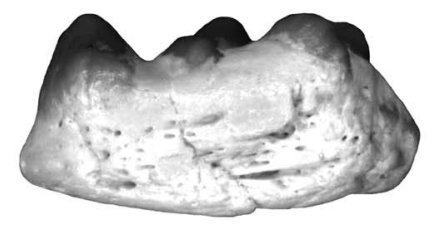

8

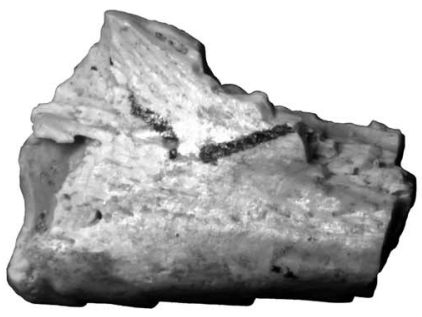

11

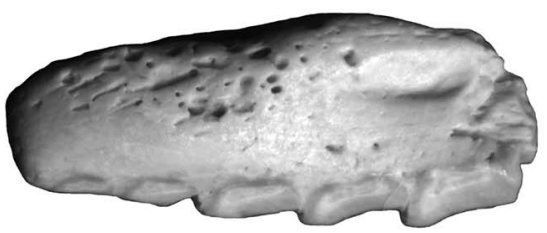

14

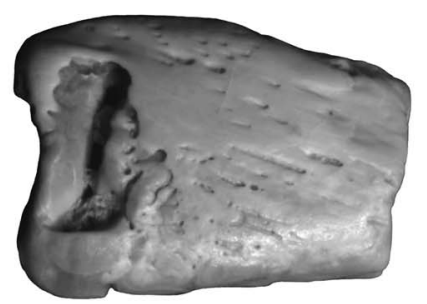

3

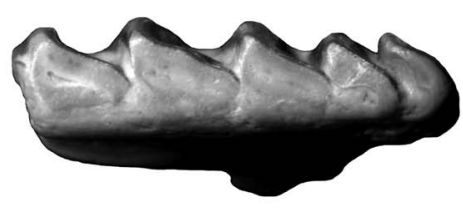

6

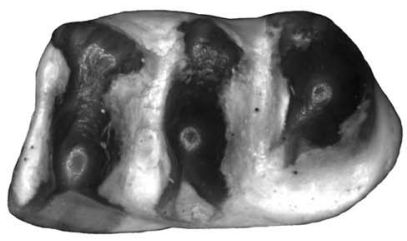

9

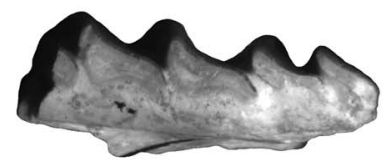

12

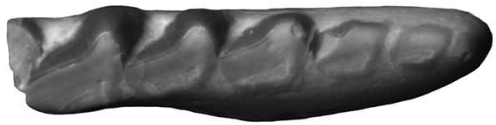

15

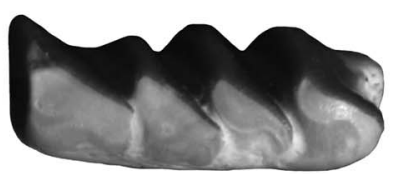

Figure 1. Fraserosphenodon latidens n. comb.; all specimens shown in labial, lingual, and occlusal views: (1-3) VMNH 524, holotype, left maxilla; (4-6) VMNH 525, paratype, right dentary; (7-9) VMNH 526, paratype, left maxilla; (10-12) VMNH 527, paratype, right maxilla; (13-15) VMNH 528, paratype, left maxilla. Scale bars = $5 \mathrm{~mm}(\mathbf{1 - 3}, \mathbf{7 - 9}, \mathbf{1 0 - 1 2}) ; 3.5 \mathrm{~mm}(\mathbf{4 - 6}, \mathbf{1 3 - 1 5})$. 


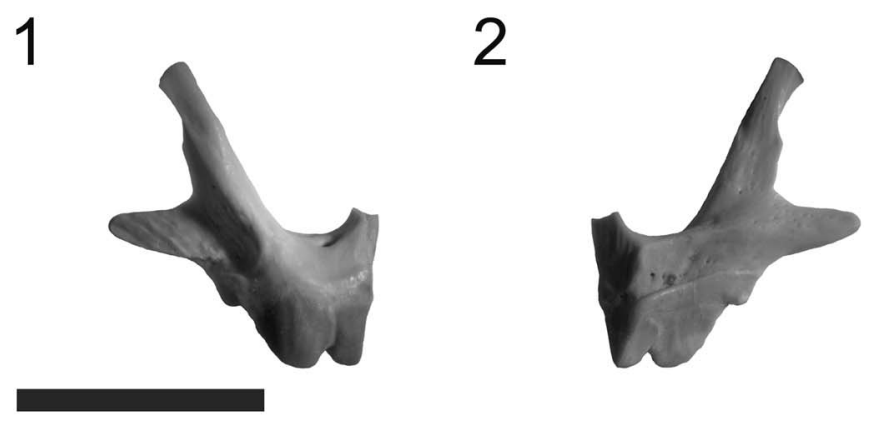

of AUP 11192, as preserved, are $10.5 \mathrm{~mm}$ and $5.4 \mathrm{~mm}$, respectively.

\section{Phylogenetic analyses}

The parsimony analysis found 7176 MPTs of 265 steps, and the $50 \%$ majority rule consensus tree shows good resolution for most clades (Fig. 3.1). The consistency (CI) and retention indices (RI) for the 50\% majority rule consensus tree are 0.38628 and 0.66403 , respectively. No clade had a Bremer support score $>1$ (complete statistics and associated files for both phylogenetic analyses can be found in the Supplemental Data). Generally, our results agree with those of other recent studies (Rauhut et al., 2012; Martínez et al., 2013; Apesteguía et al., 2014; Cau et al., 2014; Hsiou et al., 2015). One of the major differences is that our analysis recovered Pleurosauridae as the sister group of Sphenodontidae. The terrestrial Pamizinsaurus Reynoso, 1997 is the earliest diverging taxon within the Sphenodontidae, which includes two major clades. The first clade includes Ankylosphenodon Reynoso, 2000, Derasmosaurus Barbera and Macuglia, 1988, Oenosaurus Rauhut et al., 2012, and Zapatadon Reynoso and Clark, 1998 in a polytomy, whereas the second clade is well resolved, recovering the Early Jurassic Cynosphenodon Reynoso, 1996 and the modern Sphenodon Gray, 1831 as successive sister taxa to the clade comprising Theretairus Simpson, 1926 and Sphenovipera Reynoso, 2005. The strict consensus tree of the second analysis of Cau et al. (2014) also found Derasmosaurus, Oenosaurus, and Zapatadon in a similar polytomy, and forming the sister group of the clade comprising Sphenodon, Cynosphenodon, Sphenovipera, Kawasphenodon Apesteguía, 2005, and Theretairus. The close relationship of Sphenovipera and Theretairus has been constantly recovered in previous analyses (e.g., Martínez et al., 2013; Apesteguía et al., 2014; Hsiou et al., 2015).

Within clevosaurs, Brachyrhinodon Huene, 1910 was recovered as the earliest diverging taxon. All Clevosaurus species are grouped in a polytomy, which obscures the relationships between the species. The results for clevosaurs are quite similar to those recovered by the strict consensus tree of Hsiou et al. (2015). The only difference is that in their analysis, Polysphenodon Jaekel, 1911 appears as the earliest diverging taxon

Figure 2. Fraserosphenodon latidens n. comb.: (1, 2) AUP 11191, right premaxilla, shown in labial (1) and lingual (2) views; (3-5) AUP 11192, right dentary, shown in labial (3), lingual (4), and occlusal (5) views. Scale bars $=6 \mathrm{~mm}(\mathbf{1}, \mathbf{2}) ; 3.5 \mathrm{~mm}(\mathbf{3 - 5})$.

The specimen includes three generations of teeth, but caniniform teeth are lacking. The front of AUP 11192 has two rounded successional teeth similar to those of the premaxilla. These teeth are followed by a series of six or seven small semicircular remnants of hatchling teeth with minor signs of wear on the occlusal surfaces. On the distal end of this element, we found three or four additional teeth that in both labial and lingual view show the same triangular shape seen in VMNH 525. In occlusal view, the teeth of AUP 11192 show heavy signs of wear and the round, bulbous shape seen in VMNH 525. This round, bulbous shape is more pronounced in the distalmost additional tooth of AUP 11192. Additionally, AUP 11192 includes three mental foramina of relatively large size (Fig. 2.3), which suggests that this specimen comes from a juvenile. The length and height within Clevosauridae, but all other taxa were recovered in a polytomy. A similar polytomy for clevosaurs was also shown in the strict consensus tree of Rauhut et al. (2012). Our results agree with the work of Martínez et al. (2013) and Hsiou et al. (2015) in recovering Fraserosphenodon latidens as an early diverging opisthodontian. Indeed, we recovered $F$. latidens as the earliest diverging taxon within Opisthodontia. This clearly confirms that $F$. latidens is not referable to the genus Clevosaurus, and supports the erection of a new opisthodontian genus, as previously suggested (Jones, 2006a, 2009; Martínez et al., 2013; Hsiou et al., 2015; Klein et al., 2015). Within Opisthodontia, the relationships of eilenodontines are quite well resolved; our results only differ from the works of Martínez et al. (2013) and Cau et al. (2014) in finding Ankylosphenodon outside of Opisthodontia.

Another major difference compared to the previous analyses of Martínez et al. (2013) and Hsiou et al. (2015) is that the Triassic taxon Pelecymala was no longer recovered as closely 

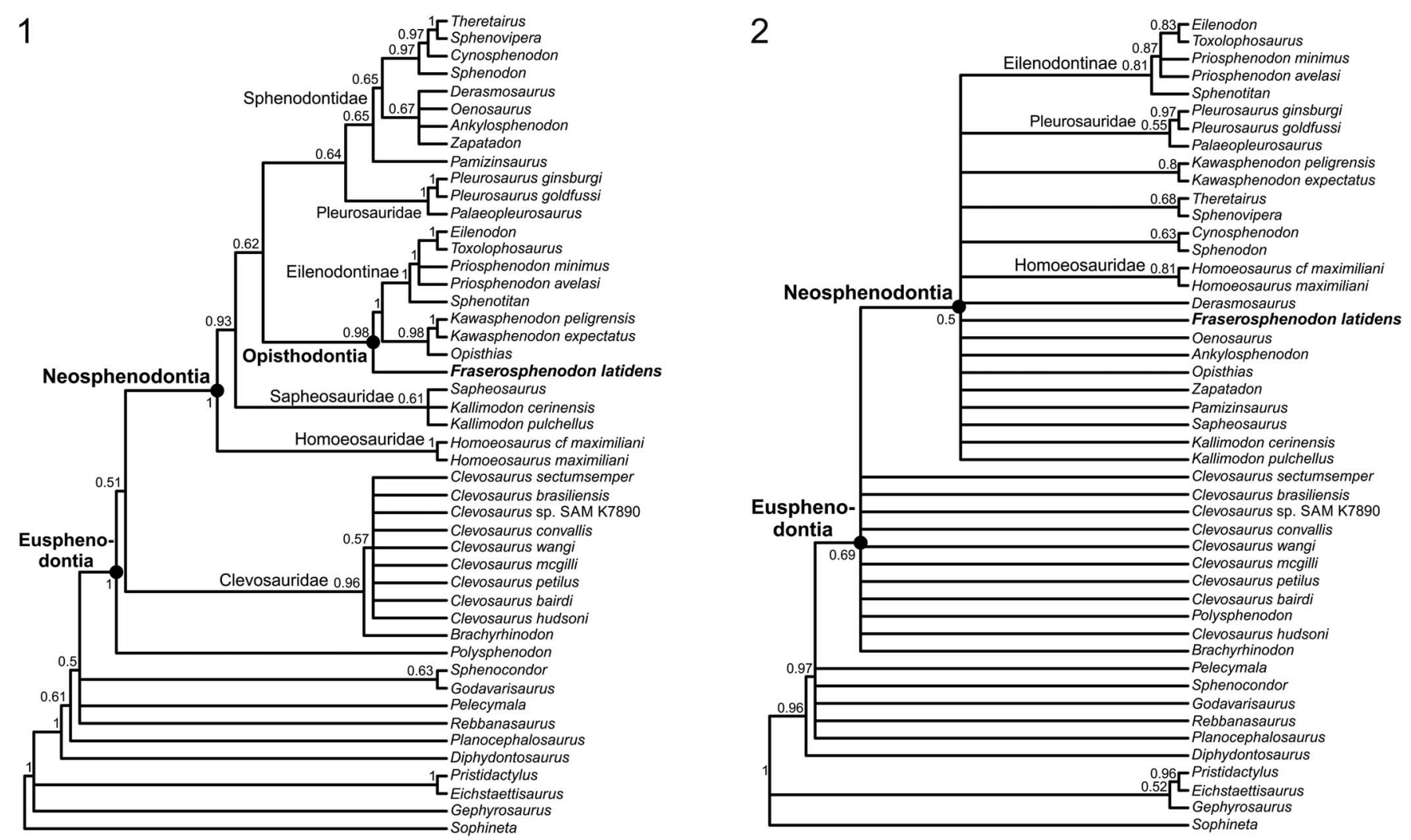

Figure 3. Consensus trees recovered from the phylogenetic analyses: (1) maximum parsimony $50 \%$ majority rule consensus tree; $\mathrm{CI}=0.38628, \mathrm{RI}=0.66403$; node labels denote the proportion of MPTs that recover that node; (2) $50 \%$ majority rule consensus tree from the Bayesian-inference analysis, with clade credibility values (decimal proportions) labeled on the nodes.

related to Opisthodontia, but was found in a polytomy with early-diverging rhynchocephalians such as Rebbanasaurus Evans, Prasad, and Manhas, 2001, the clade of Sphenocondor Apesteguía, Gomez, and Rougier, 2012 and Godavarisaurus Evans, Prasad, and Manhas, 2001, and the clade Eusphenodontia.

Overall, the results of the Bayesian analysis (Fig. 3.2) resemble those of the parsimony analysis, but with considerably less resolution. Several large polytomies were recovered, but where clades are resolved, the clade credibility values are often moderately high. The Bayesian 50\% majority rule consensus tree also recovered Pelecymala in a polytomy with early diverging rhynchocephalians, which confirms that this taxon is not related to opisthodontians as previously assumed (Martínez et al., 2013; Hsiou et al., 2015). The Bayesian tree did not recover clevosaurs as a monophyletic group; all of them were recovered in a large polytomy that obscures the relationships between the taxa. Relationships among other, later-diverging rhynchocephalians are unclear; many of them are part of a polytomy that includes Fraserosphenodon, but no clevosaurs. This result confirms that Fraserosphenodon is not closely related to Clevosaurus.

It should be noted that the Bayesian tree recovered a close relationship between the extant Sphenodon and the Jurassic Cynosphenodon, a close relationship between Theretairus and Sphenovipera, and pleurosaurs as a monophyletic group. The Bayesian tree did not recover Opisthodontia as a monophyletic group, but completely agrees with the parsimony tree for the interrelationships of eilenodontines, which are quite robust and well resolved.

\section{Discussion}

Among Mesozoic rhynchocephalians, clevosaurs were one of the most diverse groups. Clevosaurs are represented by three genera: Polysphenodon, Brachyrhinodon, and Clevosaurus. The first two genera are monospecific, whereas Clevosaurus currently has nine formally recognized species. The high diversity of the genus Clevosaurus, however, is debatable because of the doubtful validity/referral of some of the species, especially those based on poorly preserved or very fragmentary material, such as the three Chinese species (C. mcgilli, C. petilus, and C. wangi) or ' $C$. latidens' from Great Britain. According to Jones (2006a), the Chinese specimens are too poorly preserved to diagnose them as three distinct species, but clearly all of them belong to Clevosaurus. In contrast to the Chinese specimens, the referral of ' $C$. latidens' to Clevosaurus has been widely questioned (Jones, 2006a, 2009; Martínez et al., 2013; Hsiou et al., 2015; Klein et al., 2015).

Before the description of 'Clevosaurus latidens,' specimen AUP 11192, a dentary fragment, was tentatively related to Pelecymala based on its transversely wide teeth (Fraser, 1986). When Fraser (1993) formally described 'C. latidens,' he noted that the tooth morphology of the new 'Clevosaurus' species was quite similar to that of other taxa with transversely wide teeth such as P. robustus and Toxolophosaurus cloudi Olson, 1960 
(Fraser, 1993). Some of the diagnostic characters of the genus Clevosaurus based on features of the skull could not be observed in ' $C$. latidens' for obvious reasons. However, at least the dentition of ' $C$. latidens' did not match that of Clevosaurus, which consists of larger, blade-like teeth with lateral flanges. It has been suggested that the tooth morphology of Clevosaurus was very specialized for a possible omnivorous or carnivorous diet (Jones 2006b, 2009; Rauhut et al., 2012; Martínez et al., 2013), whereas the dentary and maxillary teeth ' $C$. latidens' were more like those of herbivorous taxa. Fraser (1993) also pointed out that the wear facets on the teeth of ' $C$. latidens' suggested a propalinal movement of the lower jaw, which contrasts with the orthal jaw movement seen in Clevosaurus.

Based on dentary, maxillary, and premaxillary tooth morphology, as well as the suggested propalinal movement of the lower jaw, our review of ' $C$. latidens' specimens confirms that this taxon is not referable to Clevosaurus. Our phylogenetic analyses, including both parsimony and Bayesian approaches, confirm its position outside Clevosaurus. We rename 'C. latidens' as Fraserosphenodon latidens n. comb. The parsimony tree (Fig. 3.1) suggests that F. latidens is an earlydiverging opisthodontian, but not closely related to Pelecymala as was previously suggested by Fraser $(1986,1993)$, Martínez et al. (2013), and Hsiou et al. (2015). While reviewing the type specimens of Pelecymala (AUP 11140, 11214-11215), we noticed that the teeth of Pelecymala are not transversely broadened as had been described by Fraser (1986); in contrast, their shape is more conical, slightly curved, and labiolingually flattened. The tooth morphology of Pelecymala is actually more similar to that of some of the earliest diverging rhynchocephalians, which is also confirmed by our phylogenetic analyses (Fig. 3). A complete taxonomic redescription of Pelecymala appears necessary, but is beyond the scope of this study. The Bayesian tree (Fig. 3.2) could not recover the exact relationships of $F$. latidens, because this taxon is found in a polytomy that includes many other species. Like the parsimony analysis, however, the Bayesian approach recovered $F$. latidens as a genus distinct from Clevosaurus and not closely related to clevosaurs. Following the parsimony analysis, we consider $F$. latidens as an early diverging opisthodontian.

The parsimony analysis of Rhynchocephalia showed better resolution than the Bayesian approach. This result is not unexpected, because studies have shown that Bayesian methods are more accurate but less precise than parsimony-based analyses (O'Reilly et al., 2016). There are some minor differences between the internal branches in both trees, but several higher clades were recognized by both phylogenetic methods (Fig. 3). Some of these higher clades within Rhynchocephalia have been frequently recovered in other recent phylogenetic analyses, and have been informally named as 'crown-sphenodontians,' 'derived-sphenodontians,' or 'eupropalinals' (e.g., Apesteguía et al., 2012, 2014; Apesteguía and Carballido, 2014).

We propose formal names for two well-supported clades: Eusphenodontia and Neosphenodontia (Fig. 3). We define Eusphenodontia as the least inclusive clade containing Polysphenodon muelleri Jaekel, 1911, Clevosaurus hudsoni, and Sphenodon punctatus. In the $50 \%$ majority rule consensus tree, three unambiguous character transitions were recovered for Eusphenodontia under both ACCTRAN and DELTRAN optimization: (1) wear facets on marginal teeth of the dentary and/or on marginal teeth of the maxilla are clearly visible (character 46: 0 to 1), (2) the premaxillary teeth are merged into a chisel-like structure (character 49: 0 to 1), and (3) the palatine teeth are reduced to a single tooth row with an additional isolated tooth (character 52: 0 to 1). Neosphenodontia is defined as the most inclusive clade containing $S$. punctatus but not C. hudsoni. In the $50 \%$ majority rule consensus tree, Neosphenodontia is supported by the following six unambiguous character changes that are recovered under both ACCTRAN and DELTRAN optimization: (1) the relative length of the antorbital region is increased, reaching one-quarter to one-third of the complete skull length (character 1: 2 to 1), (2) the posterior edge of the parietal is only slightly incurved inward (character 18: 0 to 1), (3) the parietal foramen is found at the same level or anterior of the anterior border of the supratemporal fenestra (character 19: 0 to 1), (4) the palatine teeth are further reduced to a single lateral row (character 52: 1 to 2), (5) the number of pterygoid tooth rows is reduced to one or none (character 55: 1 to 2), and (6) the ischium is characterized by a prominent process on its posterior border (character 60: 1 to 2). The families Homoeosauridae, Pleurosauridae, and Sphenodontidae form in our analyses, as in others, the content of the clade Neosphenodontia. Levels of homoplasy in Eusphenodontia and Neosphenodontia are generally high, with individual character consistency indices $(\mathrm{CI})$ often $<0.5$. For both clades, no individual character has a $\mathrm{CI}$ of 1 in the $50 \%$ majority rule consensus tree (for the complete list of characters, apomorphies, and other tree statistics, see the Supplemental Data). We consider the formal naming of these higher clades necessary to facilitate future discussion about the phylogenetic relationships of rhynchocephalians.

\section{Conclusion}

This study confirms previous doubts about the referral of ' $C$. latidens' to Clevosaurus. The recognition of ' $C$. latidens' belonging to a new genus now formally named Fraserosphenodon emphasizes the high generic diversity of Rhynchocephalia in the Mesozoic, especially among herbivorous taxa. Furthermore, our study demonstrates that the use of Bayesian approaches can be useful to contrast and validate phylogenies that were previously based only on parsimony methods. Bayesian inference exhibits generally lower resolution in some parts of the tree, but a few higher clades are strongly supported and are consistently recovered by both Bayesian and parsimony analyses.

\section{Acknowledgments}

We thank A. Hastings (VMNH) for the loan of type specimens of Fraserosphenodon. We also thank T. Colin (AUP), M. Lowe (UMZC), and J. Hanson (BRSUG) for access provided to their collections. We thank N. Fraser (NMS) for his assistance to JAH-F during his visit to Aberdeen, and D. Whiteside (University of Bristol) for his helpful comments and discussions on Clevosaurus. This work was funded by a Ph.D. scholarship from CONACYT, Mexico, and Bob Savage Memorial Fund 
from University of Bristol to JAH-F, NERC grant NE/I027630/1 to MJB and TLS, and NERC grant NE/L002434/1 to AE.

\section{Accessibility of supplemental data}

Data available from the Dryad Digital Repository: https://doi. org/10.5061/dryad.9n153

\section{References}

Apesteguía, S., 2005, A late Campanian sphenodontid (Reptilia, Diapsida) from northern Patagonia: Comptes Rendus Palevol, v. 4, p. 663-669.

Apesteguía, S., and Carballido, J.L., 2014, A new eilenodontine (Lepidosauria, Sphenodontidae) from the Lower Cretaceous of central Patagonia: Journal of Vertebrate Paleontology, v. 34, p. 303-317.

Apesteguía, S., and Novas, F.E., 2003, Large Cretaceous sphenodontian from Patagonia provides insight into lepidosaur evolution in Gondwana: Nature, v. 425 , p. $609-612$.

Apesteguía, S., Gómez, R.O., and Rougier, G.W., 2012, A basal sphenodontian (Lepidosauria) from the Jurassic of Patagonia: New insights on the phylogeny and biogeography of Gondwanan rhynchocephalians: Zoological Journal of the Linnean Society, v. 166, p. 342-360.

Apesteguía, S., Gómez, R.O., and Rougier, G.W., 2014, The youngest South American rhynchocephalian, a survivor of the K/Pg extinction: Proceedings of the Royal Society of London B, v. 281, no. 20140811, doi: 10.1098/ rspb.2014.0811.

Barbera, C., and Macuglia, L., 1988, Revisione dei tetrapodi del Cretacico Inferiore di Pietraroia (Matese Orientale, Benevento) appartenenti alla collezione Costa del Museo di Paleontologia dell'Università di Napoli: Memorie della Società Geologica Italiana, v. 41, p. 567-574.

Bonaparte, J.F., and Sues, H.D., 2006, A new species of Clevosaurus (Lepidosauria: Rhynchocephalia) from the Upper Triassic of Rio Grande do Sul, Brazil: Palaeontology, v. 49, p. 917-923.

Bremer, K., 1994, Branch support and tree stability: Cladistics, v. 10, p. 295-304.

Cau, A., Baiano, M.A., and Raia, P., 2014, A new sphenodontian (Reptilia, Lepidosauria) from the Lower Cretaceous of southern Italy and the phylogenetic affinities of the Pietraroia Plattenkalk rhynchocephalians: Cretaceous Research, v. 49, p. 172-180.

Cree, A., 2014, Tuatara: Biology and Conservation of a Venerable Survivor: Canterbury, New Zealand, Canterbury University Press, 584 pp.

Duffin, C.J., 1995, The first sphenodontian remains (Lepidosauromorpha, Reptilia) from the Late Triassic of the Gaume (southern Belgium): JurassicTriassic vertebrates: Bulletin de la Société Belge de Géologie, v. 104, p. 35-41.

Evans, S.E., and Borsuk-Białynicka, M., 2009, A small lepidosauromorph reptile from the Early Triassic of Poland: Palaeontologia Polonica, v. 65 , p. $179-202$.

Evans, S.E., Prasad, G.V.R., and Manhas, B.K., 2001, Rhynchocephalians (Diapsida: Lepidosauria) from the Jurassic Kota Formation of India: Zoological Journal of the Linnean Society, v. 133, p. 309-334.

Fraser, N.C., 1986, New Triassic sphenodontids from south-west England and a review of their classification: Palaeontology, v. 29, p. 165-186

Fraser, N.C., 1988, The osteology and relationships of Clevosaurus (Reptilia: Sphenodontida): Philosophical Transactions of the Royal Society of London B, v. 321, p. 125-178.

Fraser, N.C., 1993, A new sphenodontian from the early Mesozoic of England and North America: Implications for correlating early Mesozoic continental deposits, in Lucas, S.G., and Morales, M., eds., The Nonmarine Triassic: New Mexico Museum of Natural History and Science Bulletin, v. 3, p. 135-139.

Fraser, N.C., and Benton, M.J., 1989, The Triassic reptiles Brachyrhinodon and Polysphenodon and the relationships of the sphenodontids: Zoological Journal of the Linnean Society, v. 96, p. 413-445.

Goloboff, P.A., and Catalano, S.A., 2016, TNT version 1.5, including a full implementation of phylogenetic morphometrics: Cladistics, v. 32, p. $221-238$

Goloboff, P.A., Farris, J.S., and Nixon, K.C., 2008, TNT, a free program for phylogenetic analysis: Cladistics, v. 24, p. 774-786.

Gray, J.E., 1831, Note on a peculiar structure in the head of an Agama: Zoological Miscellany, v. 1, p. 13-14

Gray, J.E., 1842, Description of two hitherto unrecorded species of reptiles from New Zealand (Hatteria punctata and Naultinus elegans): Zoological Miscellany, v. 4, p. 72.

Gray, J.E., 1845, Catalogue of the specimens of lizards in the collection in the British Museum: London, British Museum (Natural History), 289 p.
Günther, A., 1867, Contribution to the anatomy of Hatteria (Rhynchocephalus, Owen): Philosophical Transactions of the Royal Society of London, v. 157, p. 595-629.

Haeckel, E., 1866, Generelle Morphologie der Organismen allgemeine Grundzuge der organischen Formen-Wissenschaft, mechanisch begrundet durch die von Charles Darwin reformirte Descendenz-Theorie von Ernst Haeckel: Allgemeine Entwickelungsgeschichte der Organismen kritische Grundzuge der mechanischen Wissenschaft von den entstehenden Formen der Organismen, begrundet durch die Descendenz-Theorie, v. Volume 2: Berlin, Georg Reimer, $462 \mathrm{p}$

Herrera-Flores, J.A., Stubbs, T.L., and Benton, M.J., 2017, Macroevolutionary patterns in Rhynchocephalia: is the tuatara (Sphenodon punctatus) a living fossil?: Palaeontology, v. 60, p. 319-328.

Hsiou, A.S., De França, M.A.G., and Ferigolo, J., 2015, New data on the Clevosaurus (Sphenodontia: Clevosauridae) from the Upper Triassic of southern Brazil: PLoS One, v. 10, no. e0137523, doi: 10.1371/journal. pone. 0137523.

Huelsenbeck, J.P., and Ronquist, F., 2001, MrBayes: Bayesian inference of phylogenetic trees: Bioinformatics, v. 17, p. 754-755.

Huene, F.V., 1910, Uber einen echten Rhynchocephalen aus der Trias von Elgin, Brachyrhinodon taylori: Neues Jahrbuch für Mineralogie, Geologie und Palaeontologie, v. 2, p. 29-62.

Jaekel, O., 1911, Die Wirbeltiere: Eine Übersicht uber die fossilen und lebenden Formen: Berlin, 252 p.

Jones, M.E.H., 2006a, The Early Jurassic clevosaurs from China (Diapsida: Lepidosauria): New Mexico Museum of Natural History and Science Bulletin, v. 37, p. $548-561$.

Jones, M.E.H., 2006b, Tooth diversity and function in the Rhynchocephalia (Diapsida: Lepidosauria), in Barrett, P.M., and Evans, S.E., eds., Ninth International Symposium on Mesozoic Terrestrial Ecosystems and Biota: London, The Natural History Museum, p. 55-58.

Jones, M.E.H., 2009, Dentary tooth shape in Sphenodon and its fossil relatives (Diapsida: Lepidosauria: Rhynchocephalia): Comparative Dental Morphology, v. 13, p. 9-15.

Jones, M.E.H., Anderson, C.L., Hipsley, C.A., Müller, J., Evans, S.E., and Schoch, R.R., 2013, Integration of molecules and new fossils supports a Triassic origin for Lepidosauria (lizards, snakes, and tuatara): BMC Evolutionary Biology, v. 13, no. 20821 p.

Klein, C.G., Whiteside, D.I., de Lucas, V.S., Viegas, P.A., and Benton, M.J., 2015, A distinctive Late Triassic microvertebrate fissure fauna and a new species of Clevosaurus (Lepidosauria: Rhynchocephalia) from Woodleaze Quarry, Gloucestershire, UK: Proceedings of the Geologists' Association, v. 126, p. $402-416$.

Kuhn, O., 1958, Ein neuer Lacertilier aus dem fränkischen Lithographieschiefer: Neues Jahrbuch für Geologie und Paläontologie, Monatshefte, v. 1958, p. $437-440$

Lewis, P.O., 2001, A likelihood approach to estimating phylogeny from discrete morphological character data: Systematic Biology, v. 50, p. 913-925.

Martínez, R.N., Apaldetti, C., Colombi, C.E., Praderio, A., Fernandez, E., Malnis, P.S., Correa, G.A., Abelin, D., and Alcober, O., 2013, A new sphenodontian (Lepidosauria: Rhynchocephalia) from the Late Triassic of Argentina and the early origin of the herbi. $\mathrm{v}$, ore opisthodontians: Proceedings of the Royal Society of London B, v. 280, no. 20132057, doi: 10.1098/rspb.2013.2057.

Olson, E.C., 1960, A trilophosaurid reptile from the Kootenai Formation (Lower Cretaceous): Journal of Paleontology, v. 34, p. 551-555

O'Reilly, J.E., Puttick, M.N., Parry, L., Tanner, A.R., Tarver, J.E., Fleming, J., Pisani, D., and Donoghue, P.C., 2016, Bayesian methods outperform parsimony but at the expense of precision in the estimation of phylogeny from discrete morphological data: Biology Letters, v. 12, no. 20160081, doi: 10.1098/rsbl.2016.0081.

Parry, L.A., Edgecombe, G.D., Eibye-Jacobsen, D., and Vinther, J., 2016, The impact of fossil data on annelid phylogeny inferred from discrete morphological characters: Proceedings of the Royal Society of London B, v. 283, no. 20161378 , doi: 10.1098/rspb.2016.1378.

Puttick, M.N., O'Reilly, J.E., Tanner, A.R., Fleming, J.F., Clark, J., Holloway, L., Lozano-Fernandez, J., Parry, L.A., Tarver, J.E., Pisani, D., and Donoghue, P.C., 2017, Uncertain-tree: discriminating among competing approaches to the phylogenetic analysis of phenotype data: Proceedings of the Royal Society of London B, v. 284, , no. 20162290, doi: 10.1098/ rspb.2016.2290

Rauhut, O.W.M., Heyng, A.M., López-Arbarello, A., and Hecker, A., 2012, A new rhynchocephalian from the Late Jurassic of Germany with a dentition that is unique amongst tetrapods: PLoS One, v. 7, no. e46839, doi: 10.1371/ journal.pone.0046839.

Reynoso, V.H., 1996, A Middle Jurassic Sphenodon-like sphenodontian (Diapsida: Lepidosauria) from Huizachal Canyon, Tamaulipas, Mexico: Journal of Vertebrate Paleontology, v. 16, p. 210-221. 
Reynoso, V.H., 1997, A 'beaded' sphenodontian (Diapsida: Lepidosauria) from the Early Cretaceous of central Mexico: Journal of Vertebrate Paleontology, v. 17 , p. $52-59$.

Reynoso, V.H., 2000, An unusual aquatic sphenodontian (Reptilia: Diapsida) from the Tlayua Formation (Albian), central Mexico: Journal of Paleontology, v. 74, p. 133-148.

Reynoso, V.H., 2005, Possible evidence of a venom apparatus in a Middle Jurassic sphenodontian from the Huizachal red beds of Tamaulipas, México: Journal of Vertebrate Paleontology, v. 25, p. 646-654.

Reynoso, V.H., and Clark, J.M., 1998, A dwarf sphenodontian from the Jurassic La Boca formation of Tamaulipas, México: Journal of Vertebrate Paleontology, v. 18 , p. 333-339.

Reynoso, V.H., and Cruz, J.A., 2014, Mesozoic lepidosauromorphs of Mexico: a review and discussion of taxonomic assignments, in Rivera-Sylva, H.E. Carpenter, K., and Frey, E., eds., Dinosaurs and Other Reptiles from the Mesozoic of Mexico: Bloomington, Indiana, Indiana University Press, p. 44-78.

Robinson, P.L, 1973, A problematic reptile from the British Upper Trias: Journal of the Geological Society, v. 129, p. 457-479.

Romo de Vivar-Martínez, P.R., and Bento-Soares, M., 2015, Dentary morphological variation in Clevosaurus brasiliensis (Rhynchocephalia, Clevosauridae) from the Upper Triassic of Rio Grande do Sul, Brazil: PLoS One, v. 10, no. e0119307, doi: 10.1371/journal.pone.0119307.

Ronquist, F., Teslenko, M., Van Der Mark, P., Ayres, D.L., Darling, A., Höhna, S., Larget, B., Liu, L., Suchard, M.A., and Huelsenbeck, J.P., 2012, MrBayes 3.2: efficient Bayesian phylogenetic inference and model choice across a large model space: Systematic Biology, v. 61, p. 539-542.
Säilä, L.K., 2005, A new species of the sphenodontian reptile Clevosaurus from the Lower Jurassic of South Wales: Palaeontology, v. 48, p. 817-832.

Simpson, G.G., 1926, American terrrestrial Rhynchocephalia: American Journal of Science, v. 12, p. 12-16.

Sues, H.D., and Reisz, R.R., 1995, First record of the early Mesozoic sphenodontian Clevosaurus (Lepidosauria: Rhynchocephalia) from the Southern Hemisphere: Journal of Paleontology, v. 69, p. 123-126.

Sues, H.D., Shubin, N.H., and Olsen, P.E., 1994, A new sphenodontian (Lepidosauria: Rhynchocephalia) from the McCoy Brook Formation (Lower Jurassic) of Nova Scotia, Canada: Journal of Vertebrate Paleontology, v. 14, p. 327-340.

Swinton, W.E., 1939, A new Triassic rhynchocephalian from Gloucestershire: Journal of Natural History, v. 4, p. 591-594.

Williston, S.W., 1925, Osteology of the Reptiles: Cambridge, Massachusetts, Harvard University Press and Society for the Study of Amphibians and Reptiles, $300 \mathrm{p}$

Wright, D.F., 2017, Bayesian estimation of fossil phylogenies and the evolution of early to middle Paleozoic crinoids (Echinodermata): Journal of Paleontology, v. 91, p. 799-814.

Wu, X.C., 1994, Late Triassic-Early Jurassic sphenodontians from China and the phylogeny of the Sphenodontia, in Fraser, N.C., and Sues, H.D., eds., In the Shadow of the Dinosaurs: Early Mesozoic Tetrapods: Cambridge, UK, Cambridge University Press, p. 38-69.

Young, C.-C., 1982, On a new reptilian fossil from Lufeng, Yunnan, in Selected Works of Yang Zhungjian: Beijing, Science Press, p. 36-37.

Accepted 27 October 2017 